\title{
外来入侵植物北美车前繁殖及光合生理生态学研究
}

\author{
郭水良 ${ }^{12}$ 方 芳 $^{1}$ 黄 华 $^{1}$ 强 $^{\text {胜 }^{3}}$ \\ (1 浙江师范大学化学与生命科学学院, 浙江金华 321004) \\ （2 上海师范大学生命与环境科学学院, 上海 200234) (3 南京农业大学植物科学系, 南京 210014)
}

摘 要 北美车前 (Plantago virginica) 原产北美, 20 世纪 50 年代进入我国华东地区, 近年来其种群呈现爆发式增长 态势, 已分布到上海、浙江、江西、江苏等省区, 是一种典型的生态入侵种。本文计测了该种在不同密度下的繁殖指 标 统计了种群密度与繁殖指标间的关系; 应用 LAC-4 (ADC 英国) 光合和蒸腾系统测定了该种及其伴生杂草一年 蓬 (Erigeron annuus)、小飞蓬 (Conyza canadensis)、野塘藁( Conyza bonarinsis)、马缨丹 (Lantana camara)、空心莲子草 ( Al-

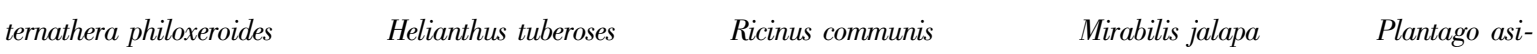
atica)、苦苍菜( Sonchus oleraceus)、羊蹄 (Rumex japonicus)、藜 (Chenopedium album) 和黄鹤菜 ( Youngia japonica) 等杂草的 光合作用指标, 作出了它们的光合-光响应曲线。主要实验结果有: :1) 北美车前个体花穗重 $\left(Y_{1}\right)$ 、花数/穗 $\left(Y_{2}\right)$ 与种 群密度 $(X)$ 呈现倒数关系 $\left(Y_{1}=0.1382+15.9598 / X, Y_{2}=46.3069+6914.07 / X\right)$; 随着种群密度增加, 北美车前 的繁殖投资 $\left(Y_{3}\right)$ 、与繁殖投资关系密切的种子数/营养器官重 $\left(Y_{4}\right)$ 呈线性增加 $\left(Y_{3}=0.0469+0.0002 X, Y_{4}=\right.$ $130.24+0.0239 X) ; 2)$ 随着北美车前种群密度的增加, 个体间的大小不整齐性 $\left(Y_{5}\right)$ 变小 $\left(Y_{5}=0.3748-0.00002\right.$ $X) ; 3)$ 种群个体间大小不整齐性 $\left(Y_{5}\right)$ 与繁殖投资 $(X)$ 呈明显负相关 $\left(Y_{5}=0.3793-0.1066 X\right)$, 即随着个体大小 不整齐性的增加，北美车前种群的繁殖投资减少; $A$ ) 以自然条件下测得的光合作用数据为基础，拟合得到了北美车 前及其它 13 种伴生杂草的光合-光响应曲线。北美车前的光合-光响应曲线符合 $Y=-7 E-06 X^{2}+0.0223 X-$ 0.8312 光补偿点、光饱和点和最大净光合速率分别为 $37.32 \mu \mathrm{mol} \mathrm{m} \mathrm{m}^{-2} \mathrm{~s}^{-1} 、 1593 \mu \mathrm{mol} \mathrm{m}^{-2} \mathrm{~s}^{-1}$ 和 $16.93 \mu \mathrm{mol} \mathrm{CO} i$ $\mathrm{m}^{-2} \mathrm{~s}^{-1}$, 说明北美车前是典型的阳生杂草。从光补偿点分析, 北美车前的耐荫能力比车前、黄鹤菜、小飞蓬、一年 蓬、野塘蓠、葲麻、加拿大一枝黄花 (Solidago canadensis)、苦苣菜、羊蹄和马缨丹的要弱 北美车前净光合速率比一年

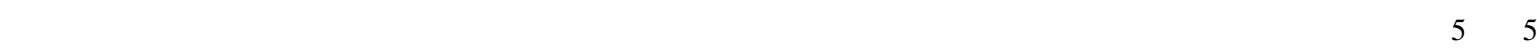
月下旬 杂草性极强的一年蓬、小飞蓬和空心莲子草的光合午休现象不明显, 逸生杂草紫茉莉具有明显的光午休现 象 北美车前是早春杂草, 在 5 月下旬也有明显的光合午休现象, 反映出该种不能够很好地适生于 5 月下旬的高温 强光环境。通过分析, 得出如下结论 : 1) 随着种群密度的增加, 北美车前产生种群自疏作用, 使个体大小不整齐性 下降; 高密度给北美车前种群造成某种逆境状态 种群以 $r$-对策的生存方式适应环境, 提高其繁殖投资, 产生尽可 能多的种子, 以保证后代的生存, 这反映出北美车前在繁殖策略上灵活的调节能力; 2) 北美车前种群在定居后, 如 果定居点不再受到人为干扰, 其种群将被快速更替, 这与其粘液性的种子、较高的光补偿点有关 3) 通过保护植被, 定植高秆植物, 减少对环境的干扰, 能够有效地治理该外来杂草。

关键词 北美车前 种群密度 繁殖投资 大小不整齐性 光合作用

\section{STUDIES ON THE REPRODUCTION AND PHOTOSYNTHETIC ECOPHYSIOLOGY OF THE EXOTIC INVASIVE PLANT , PLANTAGO VIRGINICA}

\author{
GUO Shui-Liang $^{12}$ FANG Fang ${ }^{1}$ HUANG Hua ${ }^{1}$ and QIANG Sheng ${ }^{3}$ \\ (1 College of Chemistry and Life Sciences , Zhejiang Normal University , Jinhua , Zhejiang 321004 , China) \\ (2 College of Life and Environmental Sciences, Shanghai Normal University, Shanghai 200234 , China) \\ (3 Botanical Department, Nanjing Agricultural University , Nanjing 210014 , China)
}

\begin{abstract}
Plantago virginica, an annual weed species originating from North America, was introduced into Eastern China during the 1950' s. The populations of this invasive species have spread rapidly during recent years in Zhejiang , Jiangsu, Jiangxi , Guangdong and Hunan provinces. In the present paper, reproductive indices of Plantago virginica, including spike weight per individual, flower number per spike, reproductive biomass per vegetative biomass and Gini coefficient, which indicates individual size inequality , were obtained from populations growing at different densities. The photosynthetic indices of Plantago virginica and its com-
\end{abstract}


panion species were determined using a LCA-4 portable photosynthesis and transpiration system ( ADC , England). The companion species included Erigeron annuus , Conyza canadensis , Conyza bonarinsis , Lantana camara , Mirabilis jalapa , Alternathera philoxeroides , Ricinus communis , Chenopodium album , Rumex japonicus, Plantago asiatica, Sonchus oleraceus and Helianthus tuberoses. Their net photosynthetic rates $(Y)$ and leaf photosynthetic active radiation $(X)$ were modeled using the equation $Y=a X^{2}+b X+c$.

The main experimental results are summarized below. 1) During the reproductive phase, the relationships of the population density $(X)$ with spike weight per individual $\left(Y_{1}\right)$, flower number $\left(Y_{2}\right)$, reproductive effort $\left(Y_{3}\right)$ and seed numbers per vegetative biomass $\left(Y_{4}\right)$ were as follows : $Y_{1}=0.1382+15.9598 / X, Y_{2}=$ $46.3069+6914.07 / X, Y_{3}=0.0469+0.0002 X$ and $\left.Y_{4}=130.24+0.0239 X .2\right)$ With an increase in the population density of $P$. virginica , the individual size inequality (Gini coefficient, $Y_{5}$ ) declined by the following relationship : $Y_{5}=0.3748-0.00002 X$. 3) The individual size inequality $\left(Y_{5}\right)$ was negatively related to reproductive effort $(X)$, following $Y_{5}=0.3793-0.1066 X$, which indicated that the population reproductive effort declined with an increase in individual size inequality. 4) The photosynthesis $(Y)$ - light $(X)$ response curve followed : $Y=-7 E-06 X^{2}+0.0223 X-0.8312$. The light compensation point, light saturation point and the maximum net photosynthetic rate of $P$. virginica were $37.32 \mu \mathrm{mol} \mathrm{m}^{-2} \mathrm{~s}^{-1}$, $1593 \mu \mathrm{mol} \mathrm{m} \mathrm{m}^{-2} \mathrm{~s}^{-1}$ and $16.93 \mu \mathrm{mol} \mathrm{CO} \mathrm{m} \mathrm{m}^{-2} \mathrm{~s}^{-1}$, respectively, indicating that $P$. virginica is a typical heliophyte. The shade-tolerant ability of $P$. virgincia was lower than that of Plantago asiatica , Youngia japonica , Conyza canadensis , Erigeron annuus , Conyza bonarinsis , Ricinus communis , Solidago canadensis , Sonchus oleraceus, Rumex japonicus and Lantana camara, its net photosynthetic rate was lower than that of Erigeron annuus, Conyza canadensis, Conyza bonarinsis and Solidago canadensis, but higher than that of Chenopodium album, Sonchus oleraceus, Ricinus communis and similar to that of Plantago asiatica. 5) During the last ten-day period of May , the photosynthetic midday-depression" was not apparent in the three typical weedy species (Erigeron annuus, Conyza canadensis and Alternathera philoxeroides) but obvious in $P$. virginica and the escaped species, Mirabilis jalapa. Plantago virginica is an early-spring weedy species, and the high temperature and intensive light were not suitable for its growth during the last ten-day period of May.

We drew the following conclusions based on the experimental results. 1) The high population density of $P$. virginica resulted in self-thinning, which reduced the individual size inequality. Because of environmental stress resulting from high densities, the high-density population of $P$. virginica switched to an $\mathrm{r}$-strategy to increase its reproductive output by producing more seeds in order to maintain large numbers of offspring. Obviously , Plantago virgincia had the flexibility to adapt its reproductive strategy to environmental conditions. 2) If there was no human disturbance to the recipient environments, the populations of $P$. virginica would rapidly decline in the community over five successive years due to their higher light compensation point and their mucilage seeds. 3) Our suggestions for controlling Plantago virginica include protection of vegetation, planting horticultural plants with higher stalks and reducing disturbance to the recipient environments.

Key words Plantago virginica, Population density , Reproductive effort, Individual size inequality , Photosynthesis

北美车前 (Plantago virginica) 原产北美, 1951 年 始见于江西南昌市莲塘区, 目前在上海、江苏、江西、 浙江、福建、安徽、广东、湖南、四川和台湾均有发现， 其正呈现爆发式增长态势。该种种子多,繁殖能力 强, 蔓延迅速, 常入侵和危害草坪, 也见于荒山、草 坡、路边、宅旁、疏林果园及蔬菜地，在分布上有伴人 特点。该种密度增加, 花粉量较多时, 可能会导致花 粉过敏症(郭水良等, 1996 李振宇等, 2002)。

郭水良等(1996) 发现, 北美车前主要分布于交 通路边，其传播与旅游活动有关，该种具有自花授精 与异花授精两种传粉方式 种群密度、人为干扰等在 一定程度上影响其传粉方式。郭水良等 (2002a) 应 用分形方法 ,比较了北美车前与车前 (Plantago asiat- $i c a)$ 在空间分布上的特点, 发现北美车前对人为干 扰环境的空间占有能力较强; 在新入侵地 北美车前 呈明显的集群分布, 随着北美车前种群定居时间延 长 种群密度增加, 其斑块数目呈现出少 $\rightarrow$ 多 $\rightarrow$ 少的 变化趋势，外观上北美车前种群的集群分布趋势变 弱(郭水良等,2003)。与低密度的北美车前种群相 比, 高密度北美车前植株叶绿素 $\mathrm{a} / \mathrm{b}$ 值低于低密度 种群, 而过氧化物酶活性、可溶性糖、脯氨酸含量则 高于低密度种群, 叶绿素 $\mathrm{a} / \mathrm{b}$ 的这种比值使北美车 前较好地适应了有闭的群体环境。高种群密度对于 北美车前来讲是一种逆境, 通过脯氨酸和可溶性糖 的积累, 过氧化物酶 (POD) 活性的提高, 使高密度的 北美车前种群具有一定的抗逆能力 (郭水良等, 
2002b)。北美车前形态可塑性强,随着种群密度提 高、其个体在叶数、叶长、叶宽、鲜重、根长、根重等呈 现有规律的变化, 形态学指标与种群密度存在显著 的相关性(郭水良等, 2002c)。

北美车前在入侵地种群迅速增长, 反映出它们 对新环境的适应性, 这种适应除上述提及的生理、形 态可塑性、空间分布特点外, 还可能与它们的繁殖投 资、光合生理等有关。北美车前种群密度与繁殖指 标之间的关系, 可以揭示该杂草的扩张繁殖机制上 的薄弱环节。其次, 比较生态学研究是外来入侵杂 草研究中的常用方法, 通过与近缘种、与相近生活型 种类和与成功的入侵物种生态生理学指标的比较, 有助于理解北美车前的生态适应特点和成功入侵的 生态学机制, 为该种综合治理提供理论依据。

\section{1 研究方法}

研究区域位于浙江省金华市郊, 地理坐标大致 为 $29^{\circ} 13^{\prime} \mathrm{N}, 118^{\circ} 52^{\prime} \mathrm{E}$, 为山地季风气候, 极端低温 $-9.8{ }^{\circ} \mathrm{C}$ 极端最高温为 $41.3{ }^{\circ} \mathrm{C}$, 年降水量在 1500 $\sim 1800 \mathrm{~mm}$ 之间。

1.1 种群密度、繁殖投资、个体大小不整齐性指标 的测定

在生境相近、北美车前纯种群的地段设立 18 个 面积为 $1 \mathrm{~m}^{2}$ 的样地 样地中无其它杂草伴生。在北 美车前繁殖生长期的每个样地中, 随机统计 18 30 株个体的个体鲜重、花穗重、花数、繁殖投资(花穗鲜 重/营养体鲜重)、种子总数/营养器官鲜重, 并记录 种群密度。为了解个体大小不整齐性对繁殖投资的 影响, 以每个样地北美车前个体鲜重为指标, 计算 Gini 系数(个体大小不整齐性指标)，统计 Gini 与繁 殖投资、种群密度间的关系( Weiner \& Solbrig ,1984)。

\section{2 北美车前及其伴生杂草光合指标测定}

在选择环境条件相对一致的野外自然环境, 用 便携式 LCA-4 光合-蒸腾仪开放气路系统 (英国 ADC 公司制造) 叶室入气口与离地 $3 \mathrm{~m}$ 的气杆连接, 测 定北美车前及伴生杂草的光合指标。伴生种包括加 拿大一枝黄花 (Solidago canadensis)、一年蓬 (Erigeron annuus)、小飞蓬 (Conyza canadensis)、野塘蒿 (Conyza bonarinsis)、马缨丹 ( Lantana camara) 、空心莲子草 (Alternathera philoxeroides)、菉 (Chenopedium album)、 苦苣菜 (Sonchus oleraceus) 等外来入侵杂草和菊芋 (Helianthus tuberoses)、蓄麻 (Ricinus communis)、紫茉 莉( Mirabilis jalapa) 等外来逸生杂草以及车前、羊蹄 (Rumex japonicus) 和黄鹤菜( Youngia japonica) 等土著
性杂草。

\subsection{1 光合-光响应曲线的测定}

2002 年 5 月 28 日, 时间 10:00 12:00, 用毛玻 璃片盖住叶室受光面, 通过增加或减少毛玻璃片的 块数得到所需要的不同入射光强, 使入射光强形成 一个梯度 取入射光强与对应的净光合速率得到净 光合速率与光合有效辐射强度散点图, 再用标准二 次曲线方程 $\left(Y=a X^{2}+b X+c, X\right.$ : 光合有效辐射强 度 $P A R, Y$ 浄光合速率 $P_{n}$ ) 拟合光合有效辐射与净 光合速率间的关系, 根据方程中的系数计算 $P_{n}$ 的 最大值 $\left(P_{\text {max }}=c-\left(b^{2} / 4 a\right)\right)$ 、光补偿点以及 $P_{n}$ 达 到最大值的 $P A R$ 值 $\left(P A R_{\text {max }}=-b / 2 a\right)$ 。

\subsection{2 净光合速率日进程测定}

2002 年 5 月 24 日, $7: 00 \sim 18: 40$, 间隔一定时间 测定北美车前及伴生杂草叶片的净光合速率, 每次 每种测定叶片 3 4 片, 每次测定 3 个数据, 取其平 均值, 与相应的时间得到光合作用日进程图。

\section{2 结 果}

2.1 北美车前种群密度、个体大小不整齐性、繁殖 投资间的关系

通过不同种群密度下北美车前繁殖有关的参数 计测, 得到它们与种群密度关系的散点图 (图 1), 将 不同密度的北美车前个体的花穗重、花数/穗、繁殖 投资(花穗重/营养器官重)、种子数/营养器官重、个 体大小不整齐系数 (Gini 系数) 等参数作为因变量, 以种群密度为自变量, 用各种回归模型进行分析, 得 到相关性最大的回归方程(图 1)。

图 1 表明, 北美车前个体的花穗重 $\left(Y_{1}\right)$ 、花数/穗 $\left(Y_{2}\right)$ 与种群密度 $(X)$ 呈现倒数关系: $Y=a+b / x$ $(b>0)$, 随着种群密度的增加, 花穗重 $\left(Y_{1}\right)$ 、花数/穗 $\left(Y_{2}\right)$ 急剧下降 种群密度 $(X)$ 的增加使北美车前的繁 殖投资 $\left(Y_{3}\right)$ 和与繁殖投资关系密切的种子数/营养器 官重 $\left(Y_{4}\right)$ 呈线性增加趋势, 符合 $\left(Y_{3}=0.0469+\right.$ $0.0002 X, R=0.9547)$ 和 $\left(Y_{4}=130.24+0.0239 X\right.$, $R=0.6637)$ ，两者相关性达到极显著水平。

图 1 还表明，随着北美车前种群密度 $(X)$ 的增 加, 个体大小不整齐性 $\left(Y_{5}\right)$ 差异变小, 符合 $\left(Y_{5}=\right.$ $0.3748-0.00002 X, R=0.5890)$, 随着个体间大 小不整齐性 $\left(Y_{6}\right)$ 的增加 种群的繁殖投资 $(X)$ 减少, 符合 $\left(Y_{6}=0.3793-0.1066 X, R=0.6072\right)$ 。

\section{2 北美车前的光合作用特点}

\subsection{1 北美车前光合-光响应曲线及其比较}

在自然条件下, 测定北美车前及其伴生杂草在 

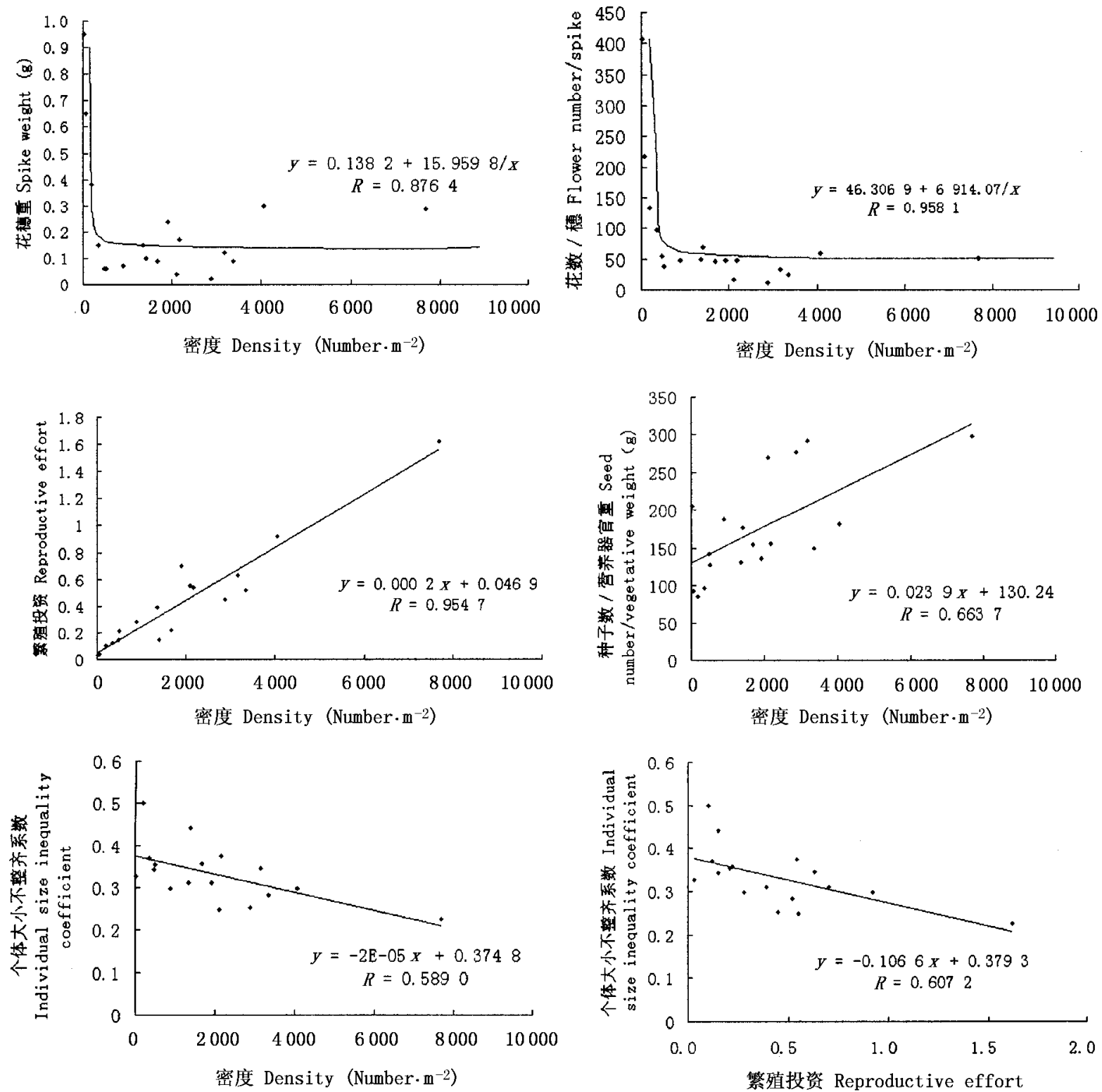

图 1 北美车前种群密度对植株形态和繁殖投资的影响

Fig. 1 The influences of population density of Plantago virginica on its morphology and reproductive effort $(p=0.01, R=0.5897 ; p=0.05, R=0.4683)$

不同叶面光合有效辐射强度下所对应的净光合速 率, 作出散点图, 得到北美车前及其它杂草的光合光响应曲线图, 北美车前及其它 12 种杂草的光合光响应曲线拟合方程见表 1 。

阳生植物的光补偿点在 $10 \sim 40 \mu \mathrm{mol} \mathrm{m} \mathrm{m}^{-2} \mathrm{~s}^{-1}$, 阴生植物的光补偿点在 $1 \sim 5 \mu \mathrm{mol} \mathrm{m} \mathrm{m}^{-2} \mathrm{~s}^{-1}$ (曹仪植 等, 1998)。外来杂草多数属于阳生植物, 多分布于 路边、住宅四周、撂荒地等受人为干扰强烈的地段。 表 1 结果也反映了这一点，北美车前表现出较高的

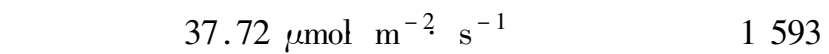
$\left.\mu \mathrm{mol} \mathrm{m} \mathrm{m}^{-2} \mathrm{~s}^{-1}\right)$, 该种的光补偿点比车前、黄鹤菜、小
飞蓬、一年蓬、野塘蓄、萫麻、加拿大一枝黄花、苦芦 菜、羊蹄和马缗丹的高, 说明北美车前比这 10 种杂 草的耐荫能力要弱。就光饱和点来讲, 北美车前的 光饱和点比蓄麻、黄鹤菜、葱、菊芋、加拿大一枝黄花 的要高, 但是比野塘蒿、马缨丹、一年蓬、苦苣菜、小 飞蓬、车前和羊蹄等的要小。说明北美车前适应强 光能力比前 5 种杂草更强, 比后 7 种的要弱。北美 车前的最大净光合速率为 $16.93 \mu \mathrm{mol} \mathrm{CO}_{2} \cdot \mathrm{m}^{-2}$. $\mathrm{s}^{-1}$ 。虽然北美车前的最大净光合速率比我国境内 广泛分布的外来杂草一年蓬、小飞蓬、野塘蕎和加拿 大一枝黄花等要低些, 但是比恶性杂草藜的要高, 也 
表 1 北美车前等 13 种杂草光合-光响应曲线方程

Table 1 Comparison of photosynthesis-light response curve equations among 13 weed species

\begin{tabular}{|c|c|c|c|c|c|}
\hline $\begin{array}{l}\text { 种类 } \\
\text { Species }\end{array}$ & $\begin{array}{c}\text { 拟合方程 } \\
\text { Equation }\end{array}$ & $\begin{array}{l}\text { 相关系数 } \\
\text { Correlation } \\
\text { coefficient }\end{array}$ & $\begin{array}{c}\text { 光补偿点 } \\
\text { Light compensation } \\
\text { point } \\
\left(\mu \mathrm{mol} \mathrm{m} \mathrm{m}^{-2} \mathrm{~s}^{-1}\right)(\end{array}$ & $\begin{array}{c}\text { 光饱和点 } \\
\text { Light saturated } \\
\text { point } \\
\left.\mu \text { mol } \mathrm{m}^{-2} \mathrm{~s}^{-1}\right)\end{array}$ & $\begin{array}{c}\text { 最大净光合速率 } \\
\text { Maximal net } \\
\text { photosynthetic rate } \\
\left(\mu \mathrm{mol} \mathrm{CO}_{2} \mathrm{~m}^{-2} \mathrm{~s}^{-1}\right)\end{array}$ \\
\hline 1 北美车前 Plantago virginica & $y=-7 \mathrm{E}-06 x^{2}+0.0223 x-0.8312$ & 0.9635 & 37.72 & 1593 & 16.93 \\
\hline 2 一年蓬 Erigeron annuus & $y=-9 \mathrm{E}-06 x^{2}+0.0306 x-0.4917$ & 0.9808 & 16.15 & 1700 & 25.52 \\
\hline 3 野塘蒿 Conyza bonarinsis & $y=-9 \mathrm{E}-06 x^{2}+0.0289 x-0.6217$ & 0.9798 & 21.66 & 1606 & 22.58 \\
\hline 4 羊蹄 Rumex japonicus & $y=-4 \mathrm{E}-06 x^{2}+0.0188 x-0.5790$ & 0.9909 & 31.00 & 2350 & 21.51 \\
\hline $\begin{array}{c}5 \text { 加拿大一枝黄花 } \\
\text { Solidago canadensis }\end{array}$ & $y=-9 \mathrm{E}-06 x^{2}+0.0278 x-0.6922$ & 0.9883 & 25.10 & 1544 & 20.76 \\
\hline 6 小飞蓬 Conyza canadensis & $y=-5 \mathrm{E}-06 x^{2}+0.0205 x-0.2843$ & 0.9782 & 13.92 & 2050 & 20.73 \\
\hline 7 马缨丹 Lantana camara & $y=-7 \mathrm{E}-06 x^{2}+0.0236 x-0.7330$ & 0.9837 & 31.35 & 1685 & 19.16 \\
\hline 8 车前 Plantago asiatica & $y=-4 \mathrm{E}-06 x^{2}+0.0172 x-1.2463$ & 0.9895 & 7.26 & 2150 & 18.37 \\
\hline 9 菊芋 Helianthus tuberoses & $y=-1 \mathrm{E}-05 x^{2}+0.0266 x-3.1091$ & 0.9728 & 122.50 & 1330 & 14.58 \\
\hline 10 藜 Chenopedium album & $y=-1 \mathrm{E}-05 x^{2}+0.0257 x-1.9602$ & 0.9750 & 78.68 & 1285 & 14.55 \\
\hline 11 苦苣菜 Sonchus oleraceus & $y=-4 \mathrm{E}-06 x^{2}+0.0144 x-0.3745$ & 0.9842 & 26.20 & 1800 & 12.59 \\
\hline 12 蓄麻 Ricinus communis & $y=-7 \mathrm{E}-06 x^{2}+0.0153 x-0.3587$ & 0.9807 & 23.70 & 1093 & 8.00 \\
\hline 13 黄鹩菜 Youngia japonica & $y=-6 \mathrm{E}-06 x^{2}+0.0135 x-0.1441$ & 0.9551 & 10.73 & 1125 & 7.45 \\
\hline
\end{tabular}

比分布广泛的阳生杂草苦苣菜、蓄麻等的要高, 与同 属杂草车前 $\left(18.37 \mu \mathrm{mol} \mathrm{CO}_{2} \mathrm{~m}^{-2} \cdot \mathrm{s}^{-1}\right)$ 比较接近。 温达志等 (2000) 等对外来杂草薇甘菊 (Mikania micrantha) 和其它 3 种伴生杂草光合作用指标的测定 表明 薇甘菊、五节芒 (Miscanthus floridulus)、鬼针草 (Bidens bipinnata)、野葛 (Pueraria lobata)、五爪金龙 (Ipomoea cairica) 的净光合速率分别为 21.56 、33.77、 24.32、16.97、14.55 $\mathrm{mmol} \mathrm{CO}_{2} \mathrm{~m}^{-2} \mathrm{~s}^{-1}$ 北美车前的 净光合速率也比杂草性很强的野葛要高, 表明北美 车前作为一种成功的入侵杂草具有光合生理基础。

\subsection{2 北美车前净光合速率日进程及其比较}

从光合作用的日进程来看, 杂草性强的一年蓬、 小飞蓬和空心莲子草光合午休现象并不强烈，相反 杂草弱的紫茉莉等具有明显的光午休现象。北美车 前是早春杂草，在光合作用的测定日期，已处于该种 生长的末期，因此 极为明显的光合午休现象反映出 该种已不能够很好地适生于 5 月下旬的高温强光环 境。

\section{3 讨 论}

3.1 北美车前个体大小不整齐性、种群密度、繁殖 投资三者间关系

高密度条件下 种群个体所能利用的水分、矿质 元素等有效资源少于低密度种群，处于一种相对不 利的环境，通过对高密度下北美车前植株的脯氨酸、 可溶性糖和 POD 活力的测定证明了这一点(郭水良 等 $2002 \mathrm{~b}$ )。统计表明 北美车前是通过提高繁殖投 资来保证其在高密度逆境条件下的种子产量。北美
车前的繁殖投资随着种群密度增加呈现线性增加， 相关性极高 表现出不利条件下该种以 $r$-对策的生 存方式适应环境,也说明了北美车前在繁殖策略上 灵活的调节能力。Abrahamson 和 Gadgil(1973)也发 现加拿大一枝黄花的繁殖投资与植物个体大小成反 比的关系。

潘晓云等(2002)研究发现,覆膜处理种群的密 度较大、个体生长旺盛, 个体间竞争强度较大, 随着 种内个体间的竞争增加，个体间的大小不整齐性也 相应增大。但是, 自然条件下 种群内个体间的大小 不整齐性受到个体间生育期、年龄、环境异质性、遗 传因素等影响。当种群密度超过一定阈值发生自疏 作用时, 种群内个体间的大小不整齐性反而会随着 密度的增高而下降。Weiner 和 Thomas (1986) 在研 究的实验种群中,也发现在有自疏现象的种群中, 随 着密度的提高, 个体大小不整齐性下降的现象。本 文的统计表明 随着北美车前种群密度的提高 种群 内个体间的大小不整齐性下降, 可能与发生了种群 自疏作用有关。

植物种群个体大小不整齐性与繁殖投资间的关 系是进化生态学研究的重要问题（潘晓云等, 2002)。潘晓云认为, 作物种群中个体大小不整齐性 与个体的繁殖输出呈反比。造成这种关系的原因在 于个体大小不整齐性的程度反映了种群中个体间竞 争强度的高低,加剧的种内竞争往往使个体更多地 将光合产物用于营养生长。本文的统计进一步证明 了潘晓云的观点, 即随着种群个体大小不整齐性的 增加, 种群的繁殖投资下降。随着北美车前种群密 

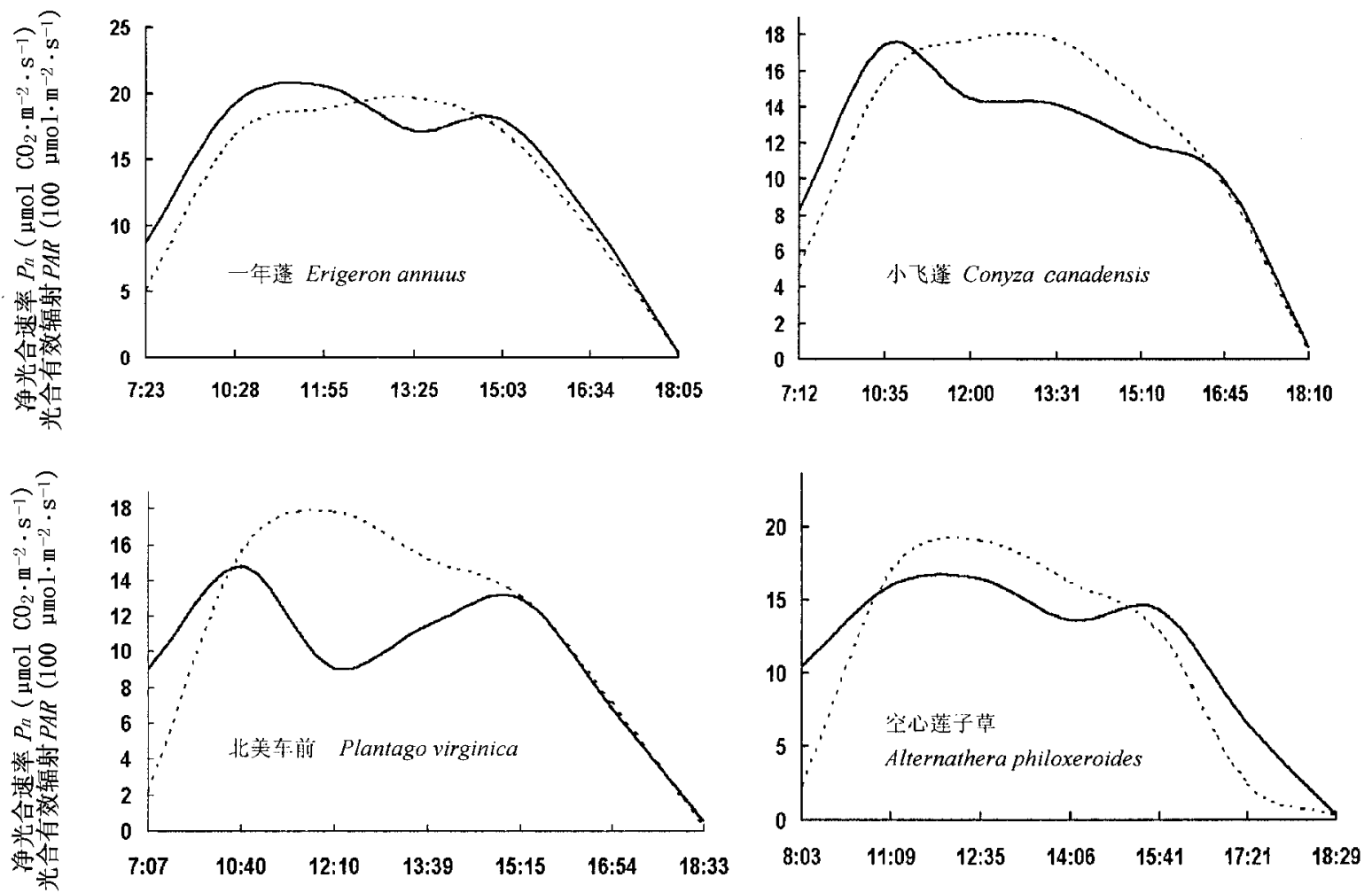

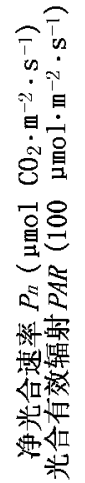

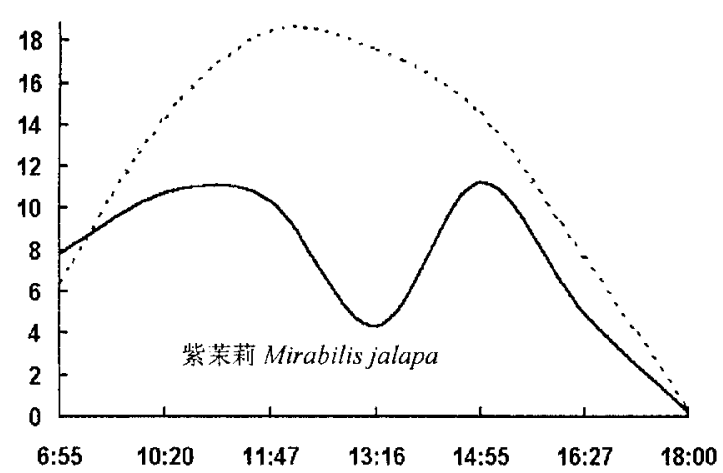

点钟 $0^{\prime}$ clock

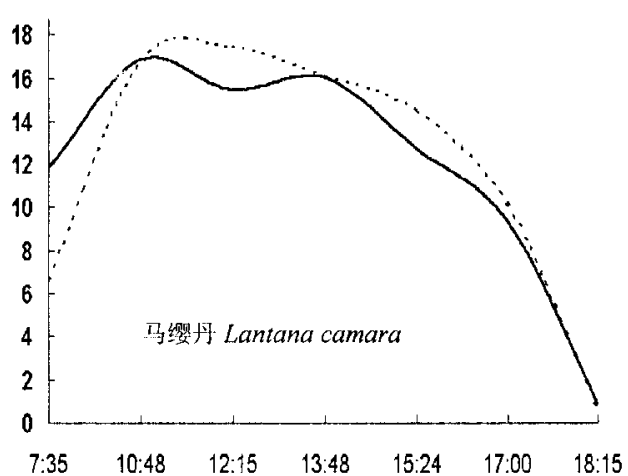

点钟 $0^{\prime}$ clock

图 2 北美车前等植物净光合速率的日进程

Fig.2 Daily course of net photosynthetic rates of six species including Plantago virginica 光合有效辐射 $P A R$ - 净光合速率 $P_{n}$

度的提高 种内竞争加剧, 高密度给个体造成一种逆 境状态(郭水良等, 2002b) ,植物在逆境中被迫以 $r$ 对策的生存策略适应环境，即采取提高繁殖投资的 方式来适应环境，同时高密度种群的自疏作用降低 了种群的个体大小不整齐性，结果显示出低密度种 群具有较高的个体大小不整齐性。

3.2 北美车前光合作用特点与其入侵地群落演替 的关系

总体上讲 北美车前具有较高的光合效率, 是一 种比较典型的阳生性杂草。该种能够利用定居初期
开阔的生境迅速扩展其种群。但是,由于该种具有 粘液性种子，风播能力又弱，母株产生的种子落于周 围(郭水良等, 1996; 李振宇等,2002), 因此, 使其种 群在定居后的 $2 \sim 3$ 年内种群密度急剧上升, 迅速形 成有闭环境。但是北美车前的耐荫能力较弱, 不能 很好地适应郁闭环境, 使其在种内和种间竞争中处 于不利地位。因此 北美车前定居后, 如果入侵地不 再受到翻耕、除草、放牧等人为干扰的影响，经过 5 年左右，该种就被其它土著种所淘汰(郭水良等， 1996）这种现象有其光合生理基础。 


\section{3 关于北美车前的管理策略}

北美车前种群的扩散主要依据其粘液性种子， 能够迅速在母株周围形成纯的种群, 造成激烈的种 内竞争 削弱了该种与土著性杂草的竞争能力, 加上 北美车前是一种阳生杂草, 具有较高的光补偿点, 因 此, 定植高秆观赏植物、降低对土壤的翻耕频度, 能 够有效地治理该外来杂草。另一方面,由于北美车 前种群具有极强的可塑性, 是典型的 $r$-对策者, 特 别适合于人为干扰强烈的阳生性环境, 加强植被保 护, 减少撂荒地、裸地是对该种最根本的管理措施。

\section{参 考 文 献}

Abrahamson, W. G. \& G. Gadgil. 1973. Growth form and reproductive effort in goldenrods (Solidago, Compositae). American Naturalist, 107: 651 661.

Cao, Y. Z. (曹仪植) \& Z. W. Song (宋占午). 1998. Plant physiology. Beijing: China Higher Education Press, $140 \sim 148$. (in Chinese with English abstract)

Guo, S. L. (郭水良)，D．X.Gu (顾德兴)，P. Liu (刘鹏)， Y. Y. Hu (胡燕月) \& Y. P. Tan (谭永平). 1996. Biological and ecological characteristics of Plantago virginica. Acta Ecologica Sinica (生态学报), 16: $302 \sim 307$. (in Chinese with English abstract)

Guo, S. L. (郭水良), D. X. Zhang (张东旭) \& J. Y. Xue (徐江余). 2002a. Fractal analysis of distribution patterns of Plantago asiatica and P. virginica. Chinese Journal of Ecology (生态学杂志), 21 (5) : 1 5 (in Chinese with English abstract)

Guo, S. L. (郭水良) \& F. Fang (方芳).2002b. Physiological indices of Plantago virginica at different population densities and their significance of adaptation to environments. Journal of Zhejiang Normal University (浙江师范大学学报), 25(1)：49～ 52. (in Chinese with English abstract)

Guo, S. L. (郭水良) \& H. Y. Sheng (盛海燕). 2002c. On influences of population density of Plantago virginica on its morphological characters. Bulletin of Botanical Research (植物研 究), 22: $236 \sim 240$. (in Chinese with English abstract)

Guo, S. L. (郭水良) \& H. Huang (黄华).2003. On intensive distributive pattern of Plantago virginica populations. Bulletin of Botanical Research (植物研究), 23: $464 \sim 471$ (in Chinese with English abstract)

Li, Z. Y. (李振宇) \& Y. Jia (解炎). 2002. Invasive alien species in China. Beijing: China Forestry Publishing House. 212. (in Chinese)

Pan, X. Y. (潘晓云)，Y．F. Wang (王永芳)，G．X. Wang (王根轩)，Q．D. Cao(曹琴东) \& J。Wang(王静)。 2002. Relationship between growth redundancy and size inquality in spring wheat populations mulched with clear plastic film. Acta Phytoecologica Sinica (植物生态学报), 26: 177 184. (in Chinese with English abstract)

Weiner, J. \& O. T. Solbrig. 1984. The meaning and measurement of size hierarchies in plant populations. Oecologia, 61: 334 336.

Weiner, J. \& S. C. Thomas. 1986. Size variability and competition in plant monoculture. Oikos, 47: 11 222 .

Wen, D. Z. (温达志), W. H. Ye (叶万辉), H. L. Feng (冯 惠玲) \& C. X. Cai(蔡楚雄) . 2000. Comparison of basic photosynthetic characteristics between exotic invader weed Mikania micrantha and its companion species. Journal of Tropical and Subtropical Botany (热带亚热带植物学报), 8(2): 139 146 . (in Chinese with English abstract) 